\title{
SOME OBSERVATIONS CONCERNING THE INCREASE OF HOSPITAL PROVISION IN LONDON BETWEEN 1850 AND 1960
}

\author{
by
}

PETER COWAN

\section{INTRODUCTION}

It is a truism that the present is contained by the past. The institutions with which we grapple in planning for tomorrow are the result of forces which were at work yesterday and the day before, and we must understand the past in order to make proper provision for the future. Nowhere does the hand of history lay more heavily than in hospital planning. For most of the hospitals in our large cities were built during the past 150 years and their age, size, location and quality affect profoundly much of our current pattern of health services. The hospitals of London illustrate graphically the problems and opportunities facing medical planners in a large industrial city. This paper describes a small part of a much wider investigation of hospital provision in metropolitan areas, which is being carried out at the Joint Unit for Planning Research of University College London and the London School of Economics. It is hoped that this investigation will result in a model or models to aid planners in deciding upon future allocations of hospital resources in growing urban areas. For the time being, however, the present paper concentrates upon some of the historical developments in a particular metropolis which illustrate the dynamics of hospital provision during a major period of metropolitan development.

\section{METHOD}

A first task was to define the area under consideration. It was decided to investigate all hospitals located within a radius of seventeen miles from St. Bartholomew's Hospital. St. Bartholomew's was chosen as the central point because it is the oldest foundation and its location has not changed very greatly over time; it is also reasonably near to the geographical centre of the London area. A radius of seventeen miles was chosen to include most of the outer suburban areas of London but not those settlements which are essentially independent of the main metropolitan complex. The area extends from Upminster in the east to Staines in the west, and from Caterham in the south to Waltham Cross in the north. All the hospitals in this area were located on maps, using as a reference the Hospitals Year Book for 1960. A postal enquiry was sent to the secretary of each hospital management committee, requesting information concerning the hospitals in his group. The secretary or house governor of each teaching hospital group was approached for similar information. Through a series of follow-up requests, it was possible to obtain information covering all the hospitals in the area.

The following information was compiled for each hospital. The date on which the present site was acquired; the present number of beds in the hospital; the present 


\section{The Increase of Hospital Provision in London between 1850 and 1960}

area of the site and information concerning the previous uses (if any) of the hospital buildings. These data were transferred to edge punch cards, one card being allocated to each hospital. The data on site acquisition were coded in ten-year periods. The number of beds in each hospital was coded in 100-bed increments. Site areas were coded in doubling units, ranging upwards from 5,000 square feet, through units of $10,000,20,000$ and so on. Information on the type of hospital (general, mental, teaching or voluntary) and on the previous history of the hospital (union, infirmary, workhouse etc.) was coded alphabetically. Finally, the distance of the hospital from the centre of the city was coded in one mile radial units.

The cards thus provided an account of the growth in number of hospitals, decade by decade, and of the increase in number of beds for the study area for each decade from 1850 onwards. Two reservations apply to these data. First, the cards only record the number of hospitals surviving in the study area in 1960 . They do not include hospitals which were founded during the period but which have since disappeared. However, by means of street directories, it was possible to pick up a number of hospitals which did disappear during the past 150 years. It was found that these were rather few in number, although they did contain certain rather interesting characteristics which could themselves be the subject of another investigation. In general it appeared that the absence of these hospitals from present-day figures should not distort significantly the overall historical picture.

The second reservation concerning the data relates to the number of beds which are accounted for. It was only possible to obtain data concerning the present size of each hospital and there may have been changes in bed numbers within each hospital during the period. However, from other investigations into patterns of growth and change in hospitals, for example Cowan and Nicholson (1964), it appears that inpatient accommodation in hospitals is less likely to change than other areas. Thus, although detailed data on changes within each hospital is lacking, it seems reasonable to suppose that such changes will be of a fairly minor nature, and will not distort the pattern too much.

From this data, it was possible to build up a picture, decade by decade, of the increase both in hospitals and in beds for various types of institutions during the past 150 years.

\section{DISCUSSION}

The study area contained 45 hospitals in 1850, and this had risen to 362 by 1960 . There were approximately 26,245 hospital beds in the study area in 1850, and 107,674 in 1960. But these increases were not uniform; certain classes of hospitals increased more quickly than others, and certain periods added more hospitals and beds than others. The general pattern of increase in the numbers of teaching, mental, and general hospitals and beds is shown in figs. 1 and 2. Although of course these figures refer only to those hospitals surviving today, and are therefore subject to some error when they refer to previous periods, they do enable us to discern some patterns.

The increase in beds over the period falls into two distinct patterns as between teaching and non-teaching hospitals, see fig. 1. Teaching hospital beds have increased in number throughout the period, at a rate which varies between 700 and 1,000 per annum; this rate has been fairly steady. In mental and general non-teaching hospitals, 


\section{Peter Cowan}

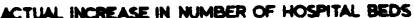

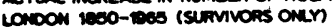

ACTUAL INCREASE IN MUMBER OF HOSPITALS LONDON 1800-1965 (SURVVORS ONLY)

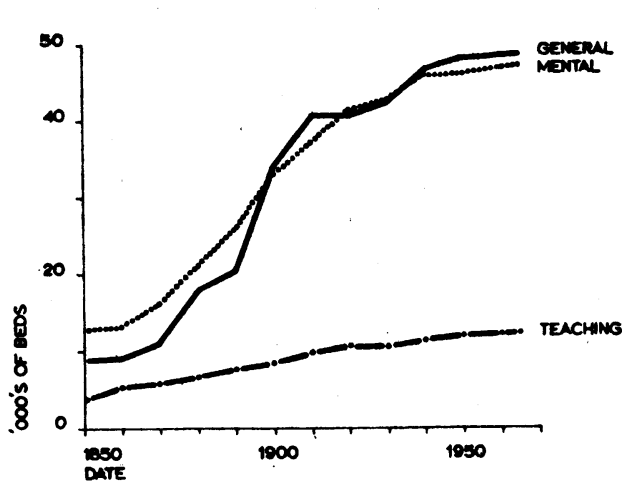

Fig. 1

ONDON GENERAL HOSPITALS

CURVE OF SPECIFIC GROWTH

(log, naof hoepitals against time)

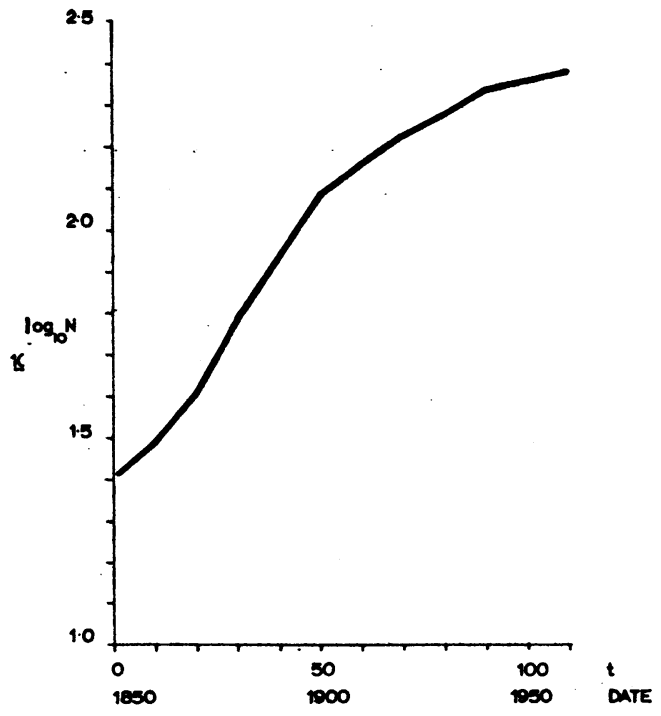

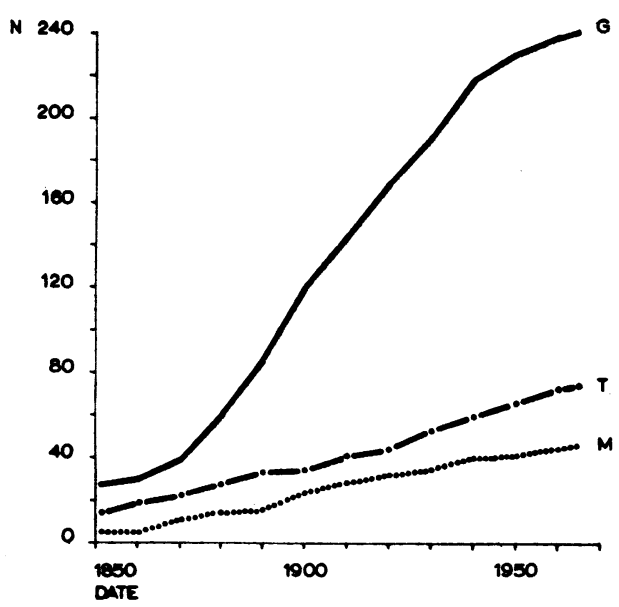

Fig. 2

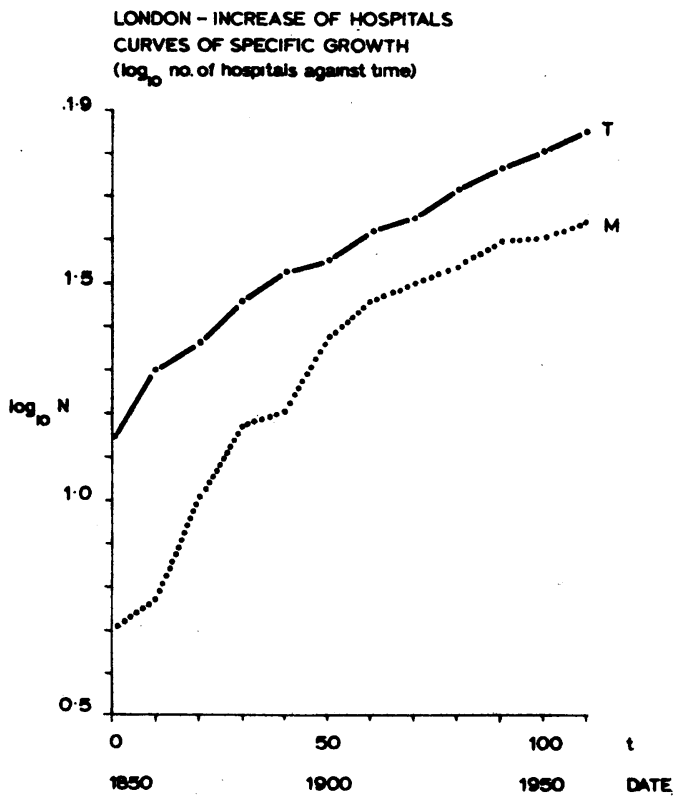

Fig. 3

Fig. 4 


\section{The Increase of Hospital Provision in London between 1850 and 1960}

the increase in number of beds had followed a very different course. In these cases the curves show a pronounced ' $S$ ' shape. Increase in number of beds was slow between 1850 and 1870 after which a period of rapid acceleration occurred. This increase continued until 1910-20 when growth slowed down. Recent growth has been very slow indeed. There is some slight difference between the curves for mental and general hospitals. The growth of general hospital beds follows a fairly smooth pattern, periods of acceleration and deceleration gradually fading into each other. Mental hospital beds, on the other hand, follow a curve with certain rather abrupt changes of direction. Between 1880 and 1900 there was a sudden sharp increase in mental hospital beds, about 17,000 being added in this twenty-year period. After 1910 the increase in beds falls off very sharply, and despite an upward tilt in 1930-40 the rate of growth never really recovers.

The curves of growth in the number of hospitals show a different pattern, see fig. 2 . Here the distinction is between general hospitals and the other classes. The number of teaching and mental hospitals increased fairly steadily over the period, at a rate of about six teaching hospitals and four mental hospitals per decade. On the other hand the number of general hospitals grew in an ' $S$ ' shaped curve, very much faster than either of the other two classes. The real 'take-off point' for this curve lies somewhere between 1860 and 1870 . Between this point and 1940 a really astonishing rate of increase was maintained, the number rising from forty-one to 220 in seventy years; an increase of some twenty-six new hospitals per decade or just over two and one half new hospitals opened every year! Bearing in mind that these figures do not include those hospitals which were opened and have since been closed, there must have been about three new hospitals opened every year in the London area for almost seventy years, a formidable record! Of course many of these hospitals were quite small, and did not make a large contribution to the total number of beds in the area, but this does not detract from the achievement of those who laid down London's hospital service.

The curve of growth is interesting in itself, but there are other curves which are even more revealing of certain facets of the pattern of growth. These have for many years been used by biologists and demographers to describe the growth of organisms and of populations, and they may be useful in describing our own 'population' of hospitals. A good general discussion of the properties of such curves is given by Medawar (1945).

The first derivative of the curve of growth is the curve of specific growth. Here, instead of plotting number against time we plot the logarithm of number against time. This is shown in figs. 3 and 4. If the number of hospitals were multiplying at a constant rate the curve of specific growth would be a straight line, and divergence from the linear form is a measure of departure from a constant growth-rate. Thus the curve of specific growth for general hospitals (fig. 3) shows very clearly the gradual increase in acceleration up to about 1900, and the subsequent deceleration. Mental hospitals also follow this pattern, but the curve for teaching hospitals is straighter, indicating a more uniform rate of growth.

For completeness we can analyse the curves of specific growth in the number of beds in each class. This is shown in fig. 5 . It can be seen that this analysis confirms 


\section{Peter Cowan}

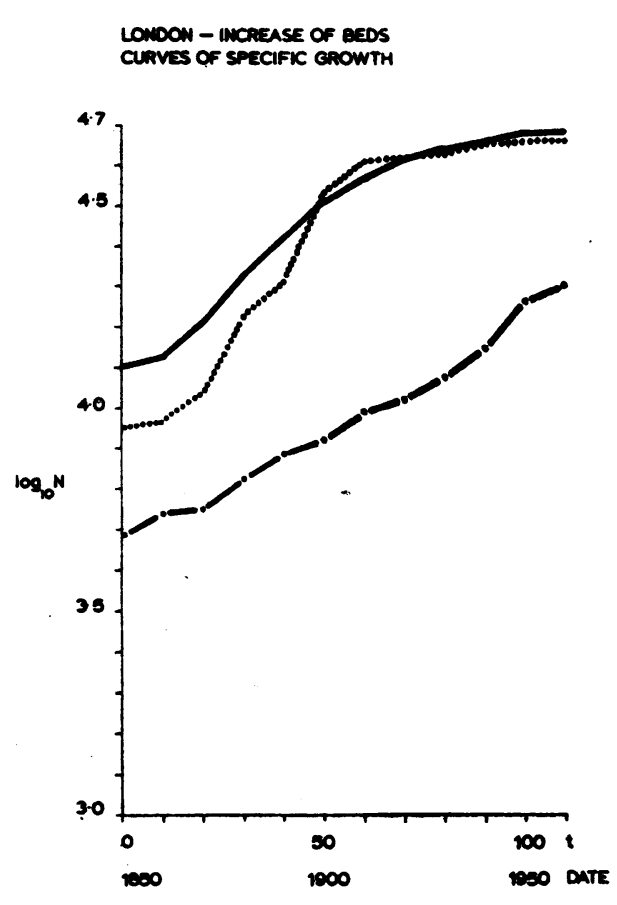

LONDON - TEACHINO HOSPTINS CRONTH RATE

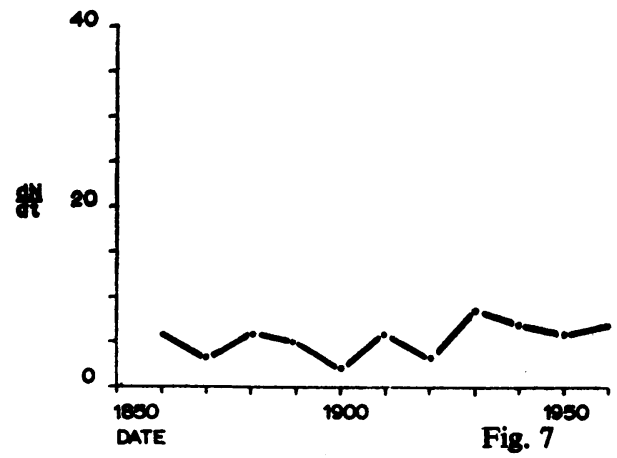

LONDON - MENTAL HOSPTALS

CROWTH RATE

Fig. 5
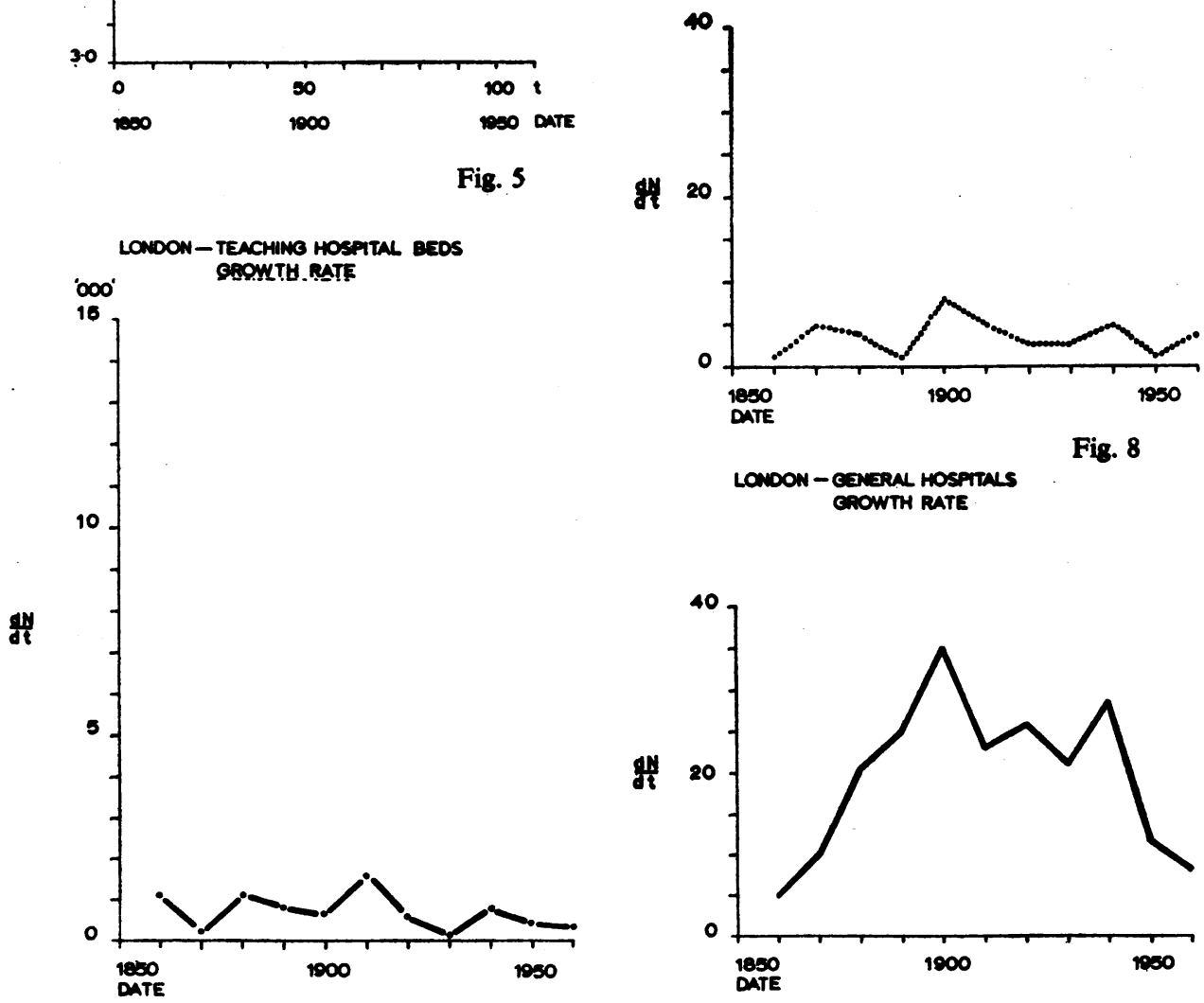

Fig. 8

LONDON - CENIRAL HOSPTALS CAOWTH RATE

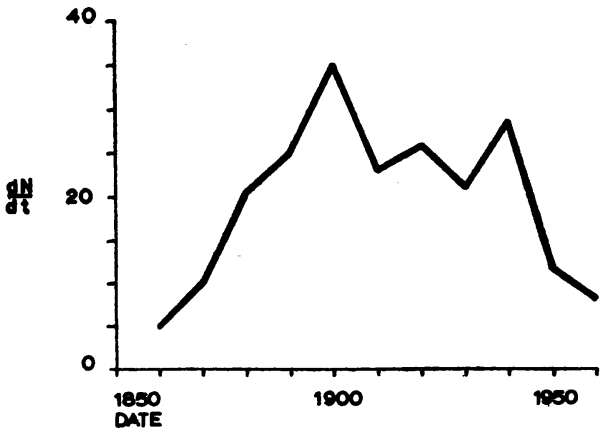

Fig. 9 
The Increase of Hospital Provision in London between 1850 and 1960

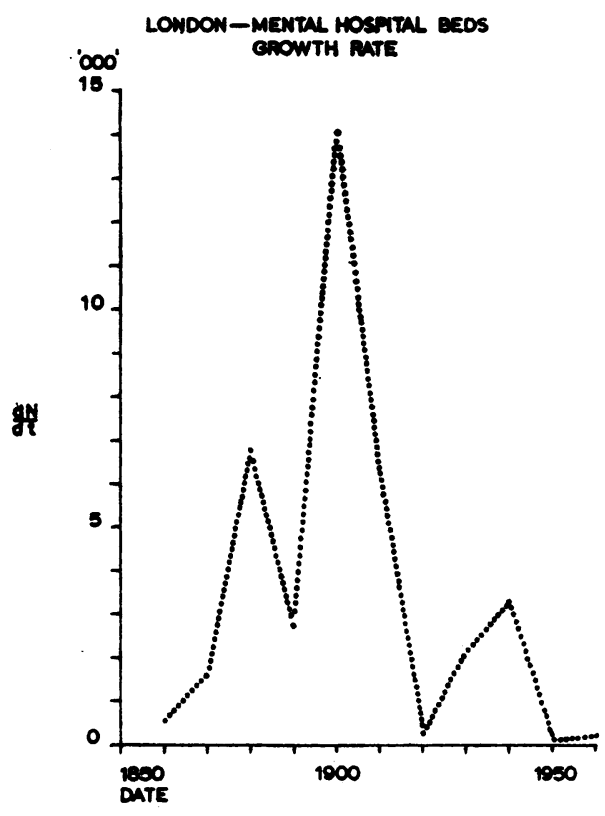

Fig. 10

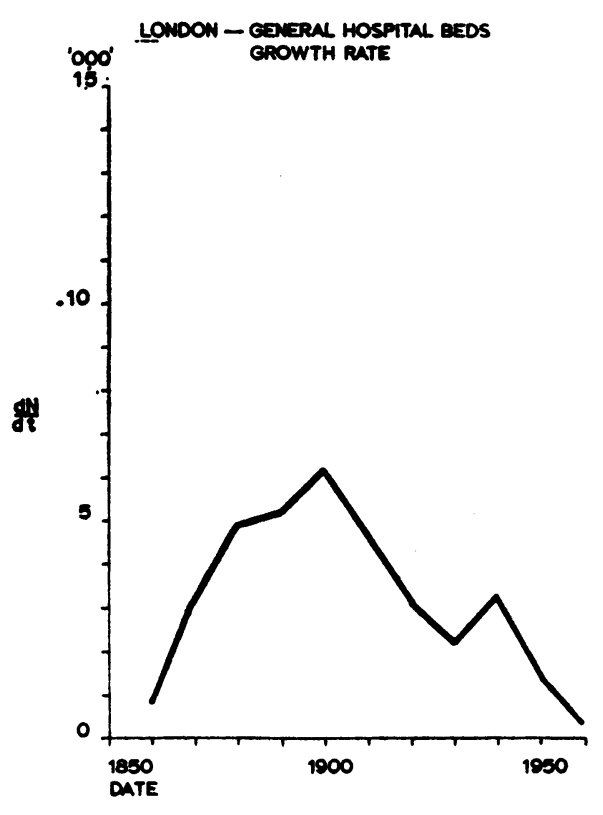

Fig. 11

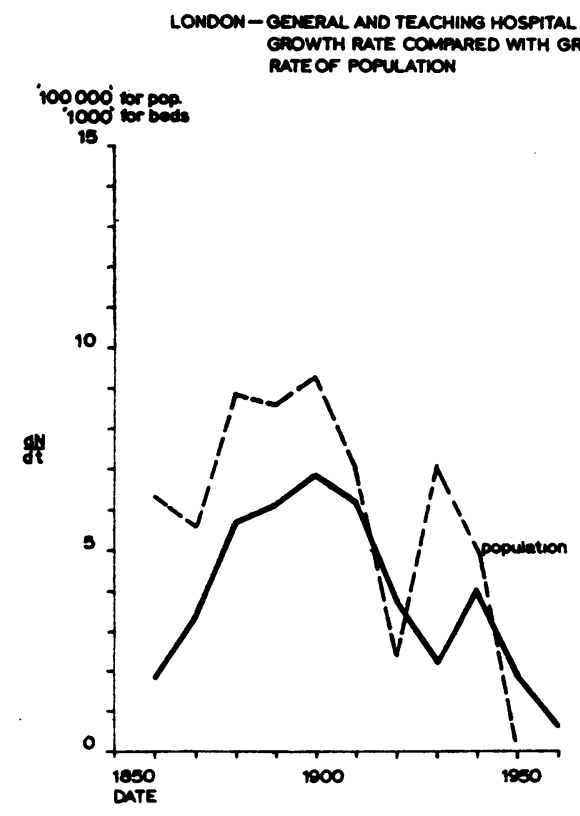

Fig. 12

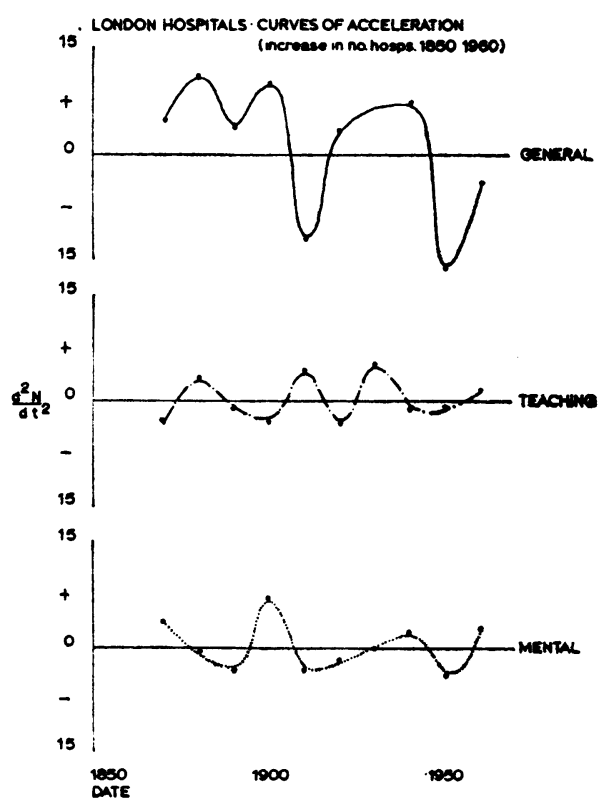

Fig. 13 


\section{Peter Cowan}

our previous observations that while the growth in teaching hospital beds has been fairly steady over the period, growth in general and mental hospital beds has slowed down since around the turn of the century. The curves are similar to those of actual growth, but they do, perhaps, reveal more clearly the speeding up and slowing up of growth at different periods.

The second curve which may be derived from the simple curve of growth is that of growth rate. In this case we differentiate $N$ with respect to $t$, giving $u s \mathrm{dN} / \mathrm{dt}$. This method was much favoured by Thompson (1917 and 1942). He states the relation between the curve of growth and that of growth-rate. 'One is the inverse of the other; one is the integral and one the differential of the other; and each makes clear to the eye phenomena which are implicit, but are less conspicuous in the other'. ${ }^{1}$ To complete the curve of growth we plot increments added during equal increments of time (as D'Arcy Thompson says, we should strictly speaking plot the increments added during equal infinitesimal increments of time) against time. We thus obtain a curve of first differences, which really shows us the velocity of growth, hence the name curve of growth rate.

The curves of growth rate in numbers of hospitals and in beds are shown in figs. 6 to 12 .

So far as the growth rate of hospitals is concerned, there are major differences between the pattern for general hospitals and other classes. The rate for teaching and mental hospitals has fluctuated within fairly narrow limits throughout the period, but the growth rate in general hospitals follows a very different and distinctive pattern. Here the curve follows a roughly parabolic shape, with a main peak around 1900 and a secondary smaller one about 1940 . It seems that the rate of growth of general hospitals may have been slowing down since the turn of the century-a point to which we shall return.

When we turn to look at the growth rate of beds in different classes of hospital, we see another set of patterns - due to the size differences between the various classes. Once again the rate of growth of teaching hospital beds has varied within narrow limits throughout the period, with a small peak about 1910. The growth rate in mental hospital beds however, has fluctuated widely from decade to decade, with a very strong peak in 1910. Once again a steady fall in the growth rate since 1910 can be seen. In general hospital beds the parabolic shape of the growth rate curve is strongly marked, a peak was reached in 1900 and the rate has steadily fallen since then with the exception of a minor peak in 1940.

These data are interesting in themselves, but they become even more fascinating if we compare them with the growth rate of population in the area. In fig. 12 a combined growth rate curve for beds in teaching and general hospitals (mental hospitals were omitted as they provide a very different kind of medical care) are compared with the growth rate of the population of London during the same period, based upon the census figures. Of course the two sets of data are not strictly comparable, since the boundaries of the hospital study area do not necessarily coincide with the census area, but even a rough comparison reveals the striking similarity in the shapes of the two curves. The growth of medical provision seems to have followed closely the

1 On Growth and Form, p. 96. 
The Increase of Hospital Provision in London between 1850 and 1960

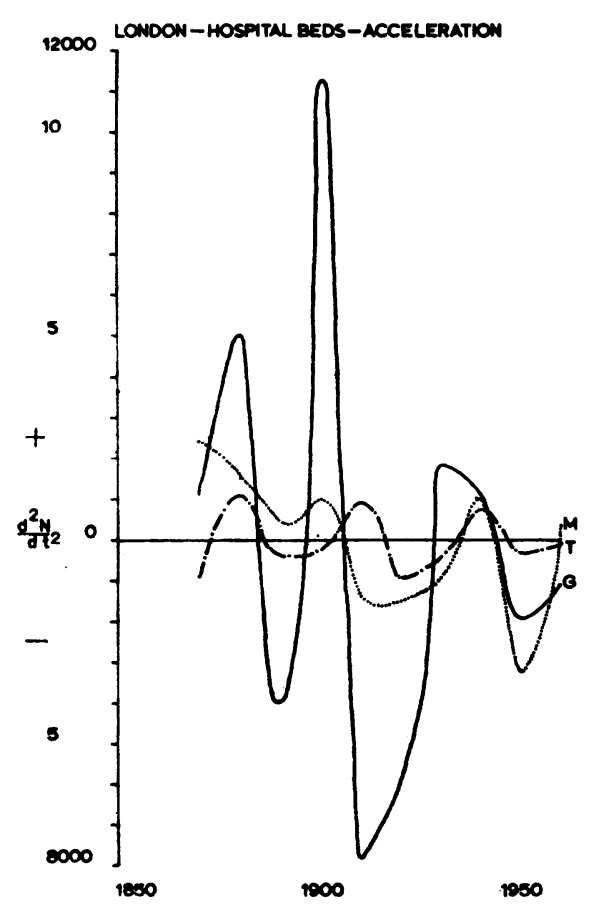

Fig. 14

LONDON-HOSPITALS

PERCENTAGE GROWTH RATE

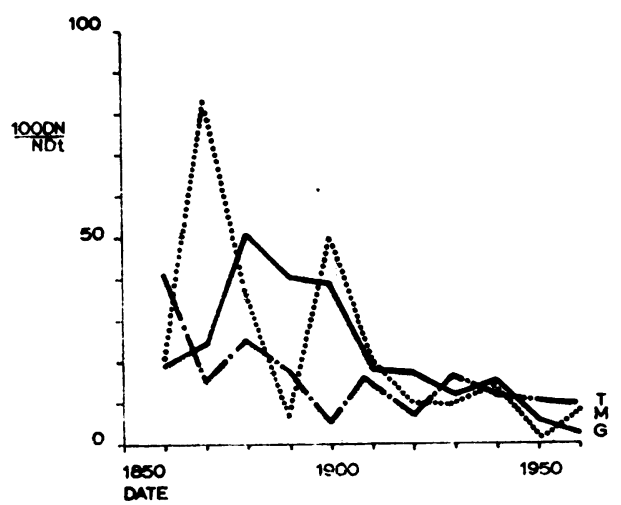

Fig. 16

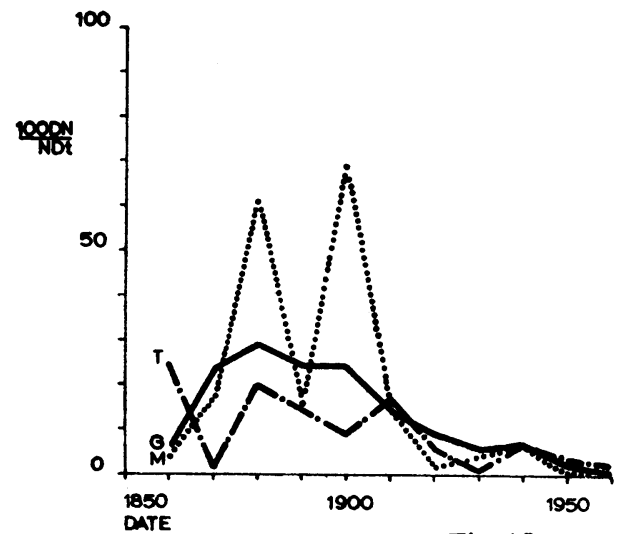

Fig. 15

LONDON-HOSPITAL BEDS

PERCENTAGE GROWTH RATE

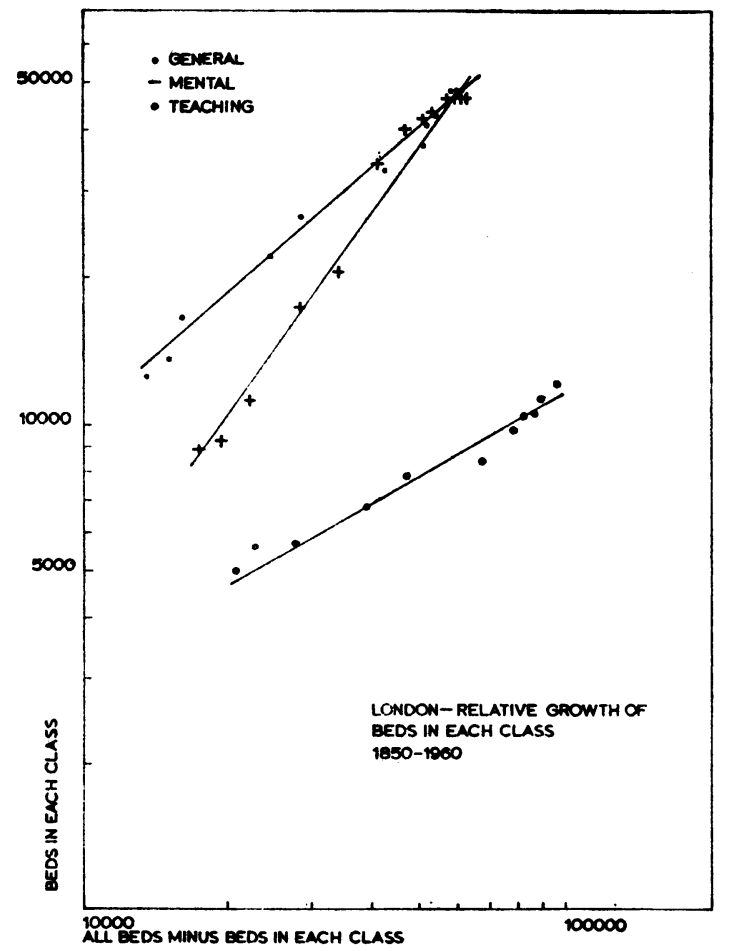

Fig. 17 


\section{Peter Cowan}

growth rate of the population of London, though with some lags as indicated by the two later peaks-one of population in 1930, and the other of hospital beds in 1940. We should expect such a lag to occur in most kinds of service provision to a changing population, as needs filter through the demand structure.

A further development from the curve of growth is the curve of acceleration. This is really a curve of second differences, and we are measuring $\mathrm{d}^{2} \mathrm{~N} / \mathrm{dt}^{2}$. Figs. 13 and 14 show the curves of acceleration in hospitals and beds during the period. The curves have some interest in that they show the speeding and slowing of the growth rate in a series of waves especially marked in the pattern of general hospitals. But the swings are so very large, especially in the case of mental hospital beds, that a coherent interpretation is difficult, and we may turn back to the growth rate and consider what further techniques we may apply in order to extract the maximum information from our basic data.

To do this we adopt a method introduced some seventy years ago by Minot (1908). Here we substitute a finite time interval $\mathrm{Dt}$ for the interval dt with respect to which number is differentiated in the algebraical procedure. If $\mathrm{DN}$ is the increment of number during the time interval Dt, Minot's 'percentage growth rate' is given by the expression $100 \mathrm{DN} / \mathrm{NDt}$. Its value may be plotted against the value of $\mathrm{t}$ which defines either the beginning of the interval Dt or its mean. D'Arcy Thompson took objection to Minot's formulation, mainly on the grounds that growth (in organisms) is continuous, and that therefore the choice of a finite, fixed Dt is erroneous. The same point is made by Brody (1926) quoted by Medawar (op. cit.), who points out that its efficiency depends not only upon the magnitude of the time interval Dt, but also upon the absolute value of $t$ around or from the beginning of which the interval is measured. These objections are valid for biological growth, which is indeed continuous, but for the phenomena we are considering the percentage growth rate can be both useful and revealing.

The percentage growth rate tells us very clearly how fast the 'population' of hospitals was growing, and whether the growth rate was speeding up or slowing down at any time. The percentage growth rate curves for the various classes of hospitals and beds are shown in figs. 15 and 16. They are especially interesting when we compare them with the curves of growth rate shown in figs. 6 to 12, for they confirm our previous evidence concerning the gradual slowing-down of hospital building which has occurred since the turn of the century. The curve of actual increase in hospitals shown in figs. 1 and 2 showed a steady increase in hospitals and beds, decade by decade; but when we look at the rate of growth, and percentage rate of increase, we see that the growth was very fast during the latter part of the nineteenth century, but has fallen off steadily since then. In the field of hospital planning a great deal of argument has been advanced about the effect of social upheavals, such as wars or depressions upon the rate of growth and increase in hospitals. In particular, the advent of the National Health Service has been said to mark an abrupt drop in the rate of hospital provision. But according to this analysis, the rate of hospital building was slowing down long before the beginning of the National Health Service, and perhaps even before the First World War. The same observation applies to the provision of hospital beds. It looks very much as if the great rush of hospital building 


\section{The Increase of Hospital Provision in London between 1850 and 1960}

in the nineteenth century satisfied in large measure the hospital requirements of London; and that growth thereafter slowed down to keep pace with the increase in population. Of course we cannot be sure that, even if the number of hospitals and beds do match the needs of London's population, they are all in the right place, and a consideration of the geographical fit between hospital provision and population forms the starting point for a model of hospital provision which is discussed elsewhere, see Cowan (1967). But for the present we should remark on the smoothness of the curves of rate of increase in the hospitals and hospital beds of London, and that this relatively smooth deceleration, in the face of social and political upheavals of great magnitude, should lead us to seek explanations which are more satisfying than the usual ones of social anecdote.

To conclude this examination we may compare the rate of growth of different classes of hospital during this period. A very clear picture of the comparative rate of growth of each class of hospital in London from 1850 to 1960 can be obtained by making use of the concept of allometry, developed by Huxley (1932) in connection with the study of relative growth rates of different parts of organisms. The basic formula of allometry runs as follows. If $x$ be the magnitude of the animal (as measured by some standard linear measurement, or by its weight minus the weight of the organ) and $y$ be the magnitude of the differentially-growing organ, then the relation between them is:

$$
y=b x^{k}
$$

where $\mathrm{b}$ and $\mathrm{k}$ are constants. Clearly this may also be written:

$\log y=\log b+k \log x$

which means that any magnitudes obeying this formula will fall along a straight line, if plotted along a double logarithmic grid. The varying slopes of such lines will give a measure of the relative rates of growth.

Our basic data is the total number of beds in each class. Thus if we plot along the $x$ axis of a double logarithmic grid, the total number of beds existing, minus the number of beds in a given class, and the number of beds in a given class along the $y$ axis, the slopes of the resulting straight lines will give us a good idea of the relative rates of growth of the different classes during the period. This is shown in fig. 17.

It can be seen that mental hospital beds have the fastest relative growth, while teaching hospital beds grow most slowly. The rate of growth in beds in general hospitals is slightly faster than that of teaching hospitals. Clearly the relative growth of each class has varied from time to time, but the general pattern is very consistent. The fast growth in mental hospital provision during the past 150 years must account for a good deal of the hospital pattern in London today.

\section{CONCLUSION}

This is a small part of a much wider investigation of the pattern of hospital provision in large cities. However, from this limited examination, certain conclusions arise. First of all, we note the striking regularity of the pattern of growth in hospital provision in the past century and a half. The rate of change in hospital provision fluctuates very little during the period, despite depressions, wars and all sorts of 


\section{Peter Cowan}

social and political changes and upheavals. Second, we should repeat our observations concerning the gradual slowing-down of hospital provision in London since about the first or second decade this century. Despite much conventional wisdom concerning the effect of various pieces of legislation and economic circumstances upon hospital provision, the data here indicate that the current rate of hospital provision is simply a continuation of a long-term trend. Finally, we must ask ourselves a question. Why is it that the increase of hospital provision in London during this period shows a pronounced S-shape curve? It is well known that the S-shape curve is common to many different growth phenomena, but it is difficult to establish why it should apply in this particular circumstance. A preliminary hypothesis might be that the slowing-down of the rate of growth which occurs in the latter part of the period, is because by about 1910 or 1920, hospital provision had caught up with the rate of growth of population and thereafter gradually slowed down to keep pace with it.

If this hypothesis is true, we should expect that, as the rate of increase in the population of the London area seems to be slowing, so hospital provision might also slow down strikingly during the next decade or so. If this is true in turn, resources could be devoted to improving and renewing existing provision rather than constructing additional facilities. This is a tendentious speculation, especially as this paper has concerned itself with the measurement of hospital care in terms of beds, whereas other facilities may be overtaking in-patient services as the major aspects of medical care. But it may be worth some attention from those responsible for planning London's hospital services, and the approach suggested here may have wider applications to other areas and different services.

\section{SUMMARY}

Information is presented concerning the number of hospitals and beds within a seventeen-mile radius of central London between 1850 and 1960. Curves of growth, of growth rate, of specific growth and of acceleration are developed. The pattern of relative growth between various classes of institution is described. A comparison is made between the growth of hospital provision and that of population in the study area. Conclusions are presented concerning secular changes in growth rates, and a hypothesis is suggested to account for such changes.

\section{REFERENCES}

BRODY, E., Research Bulletin of the University of Missouri Agricultural Experimental Station, 1926, nos. 96-98.

Cowan, P., and Nicholson, J., 'Growth and change in hospitals', Transactions of the Bartlett Society, 1964-65, vol. 3.

Cowan, P., 'Hospital systems and systems of hospitals', Transactions of the Bartlett Society, 1967-68, vol. 5.

HuXLeY, J. S., Problems of Relative Growth, London, 1932.

MrdawAr, P. B., 'Size Shape and Age' in Clark and Medawar (eds.), Growth and Form, Oxford, Clarendon Press, 1945.

Minot, C., The Problem of Age, Growth and Death, London, 1908.

Thompson, D. W., On Growth and Form, Cambridge University Press, 1917 (2nd ed., 1942). 